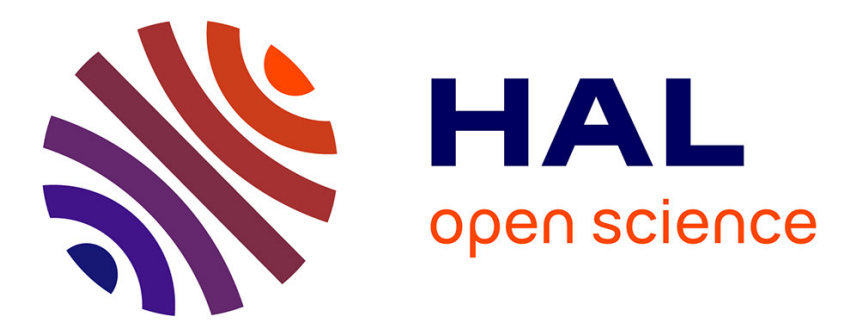

\title{
Investigating the interaction between helmet field of view and steering behavior in a novel motorcycle simulator
}

\author{
Antoine H.P. Morice, Antoine H. P. Morice, Violaine Sevrez, Rob Gray, Gilles \\ Montagne
}

\section{To cite this version:}

Antoine H.P. Morice, Antoine H. P. Morice, Violaine Sevrez, Rob Gray, Gilles Montagne. Investigating the interaction between helmet field of view and steering behavior in a novel motorcycle simulator. 8th International Driving Symposium on Human Factors in Driver Assessment, Training, and Vehicle Design, Jun 2015, Snowbird, Salt Lake City, United States. hal-02013478

\section{HAL Id: hal-02013478 \\ https://hal-amu.archives-ouvertes.fr/hal-02013478}

Submitted on 11 Feb 2019

HAL is a multi-disciplinary open access archive for the deposit and dissemination of scientific research documents, whether they are published or not. The documents may come from teaching and research institutions in France or abroad, or from public or private research centers.
L'archive ouverte pluridisciplinaire HAL, est destinée au dépôt et à la diffusion de documents scientifiques de niveau recherche, publiés ou non, émanant des établissements d'enseignement et de recherche français ou étrangers, des laboratoires publics ou privés. 


\title{
INVESTIGATING THE INTERACTION BETWEEN HELMET FIELD OF VIEW AND STEERING BEHAVIOR IN A NOVEL MOTORCYCLE SIMULATOR
}

\author{
Antoine H.P. Morice ${ }^{1}$, Violaine Sevrez ${ }^{2}$, Rob Gray ${ }^{3}$ and Gilles Montagne ${ }^{1}$ \\ ${ }^{1}$ Aix-Marseille University, Marseille, ${ }^{2}$ Lyon 1 University, ${ }^{3}$ Arizona State University \\ E-mail: antoine.morice@univ-amu.fr
}

\begin{abstract}
Summary: While helmet wearing reduces the severity of injuries in motorcycle crashes, it may also increase the likelihood of getting involved into a traffic accident through a reduction in the rider's field of view. We thus investigated the perceptual effects of helmet wearing when riding a motorcycle. The task consisted of negotiating curves in a fixed-based simulator while the helmet visor vertical dimension and need to check the handlebar-mounted speedometer were manipulated. Decreasing the vertical aperture below roughly 30 deg significantly impaired a rider's ability to maintain their lane position and speed; with the effect of aperture being significantly greater when speedometer checking was required. The present findings provide further support for near/far point models of steering and help to quantify the tradeoff between physical and perceptual effects in helmet design.
\end{abstract}

\section{INTRODUCTION}

Motorcyclists are unfortunately overrepresented in terms of traffic fatalities and motorcycle riding is the only mode of transport which has shown a consistent increase in the rate of fatalities in recent years (Bogerd et al., 2010). Wearing a certified motorcycle helmet has been shown as one of the most effective means of reducing the risk of death and head injury in motorcycle accidents (e.g., Abbas, Hefny, \& Abu-Zidan, 2012), thus motivating mandatory helmet-use laws (World Health Organization, 2006) and design standardization for impact protection (ECE/TRANS/505 RV.1/Add.21/Rev.4, 2002). However, an issue that has been primarily ignored is that a helmet designed to be optimal in terms of impact protection may directly affect the perceptual-motor behavior of the wearer that may in turn increase his/her likelihood of being involved in an accident.

The paradox between the protective effects of a motorcycle helmet and its potentially harmful side effects is most prominent when the rider's field of view is considered: the frontal aperture of a helmet should be as large as possible to provide a field of view large enough to pick up road visual information needed for steering, collision avoidance, etc (much of which is thought to come from peripheral vision), while a small aperture in required for the structural solidity of the helmet. McKnight and McKnight (1995) assessed the effects of motorcycle helmets upon visual perception by requiring 50 riders to perform lateral lane excursions in response to an audible signal under three helmet conditions: no helmet, open face, and full face motorcycle helmets. They reported that the motorcyclists' head rotation increased in proportion to the horizontal restriction of field of view imposed by the helmets. However, the effect of a restriction of the vertical field of view (which can also vary substantially amongst different helmet designs) on riding behavior remains unexplored. This is a potentially serious omission given that both far and near information sources are thought to be critical successful driving (e.g., Land \& Horwood, 1995; Salvucci \& Gray, 2004). 


\section{Aim of the present study}

The goal of the present study was to investigate the effect of varying the vertical aperture of a motorcycle helmet on performance in a simulated steering task. It was hypothesized that steering performance would be impaired for small aperture sizes. To further explore this issue we also compared two different driving tasks: one in which the rider was required to check a speedometer mounted on the handlebars (speedometer condition) and one in which they were not (free driving condition). Given that the vertical range of task-relevant information is increased in the speedometer condition, we predicted that the effect of aperture size would be larger as compared to the free driving condition.

\section{METHODS}

\section{Participants}

Eight males with no experience in motorcycle riding, and with normal or corrected to normal vision took part in the experiment. All participants held a valid car drivers license.

\section{Apparatus and Materials}

The experimental set-up (Figure 1) consisted of a custom-made fixed-based motorcycle simulator placed in front of a large projection screen $(2.3 \mathrm{~m}$ high $\times 3.0 \mathrm{~m}$ wide $)$ subtending visual angles of $117^{\circ}$ vertically and $130^{\circ}$ horizontally. Movements of the handlebar, gas lever, and front-brake lever drove potentiometers whose analog signals were converted into numeric signals (BU0836A, LeoBodnar, Silverstone, UK) before being used by an OpenGL custom-made virtual reality software. It updated in real-time the direction and speed of the motorcycle and generated the virtual scene that was back-projected at a $60 \mathrm{~Hz}$ refresh rate by a video-projector (Barco IQ R500, Patay, FR).

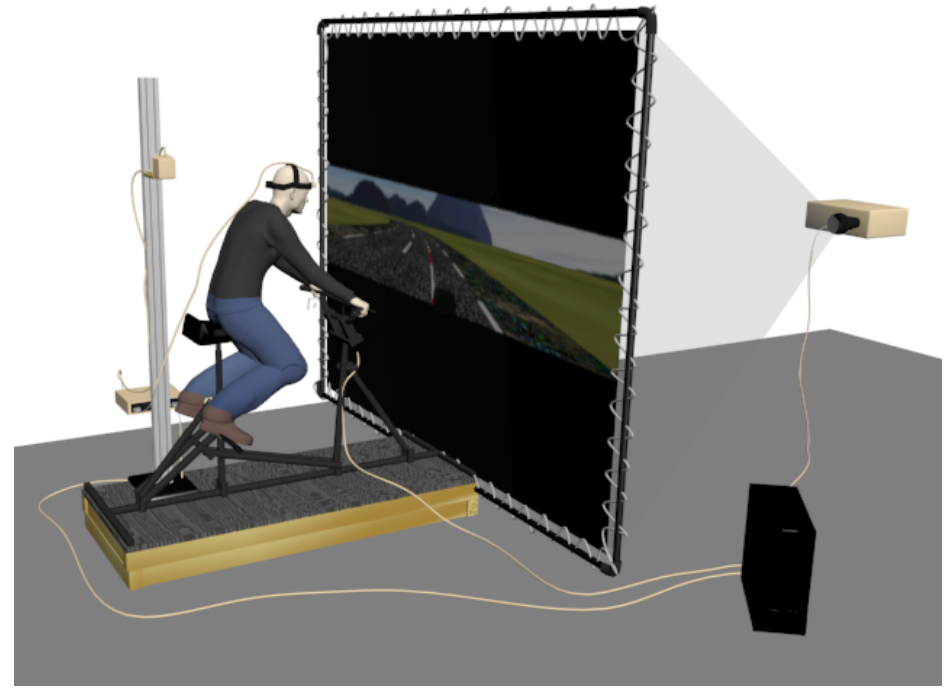

Figure 1. Motorcycle simulator 
The visual scene consisted of a ground plane textured with grass on which was superimposed a winding cement-textured road made up of two clothoids of $90^{\circ}$ oriented in opposite directions and separated by portions of straight roads. In compliance with French regulations applicable to rural roads, the road was $7 \mathrm{~m}$ wide and three white dashed-lines $(0.12 \mathrm{~m}$ wide) defined its center and lateral limits. The virtual scene further included a white and red dashed line $(0.12 \mathrm{~m}$ wide $)$ at the center of the right lane, and an instrument panel projected on the screen at a place corresponding to the center of the handlebar comprising amongst other things a speedometer $(\mathrm{in} \mathrm{km} / \mathrm{h}$ ). The optical consequence of the vertical dimension of helmet's frontal aperture on the reduction of the vertical field-of-view of riders was reproduced virtually by adjusting the gap between two horizontal black strips enslaved to the participant's head. For acoustic feedback, a set of loudspeakers played an engine sound with constant volume but with a frequency indexed on motorcycle speed.

\section{Design and Procedure}

During each trial, participants were instructed to ride as close as possible to the white and red line marking the middle of the right lane to force them to pay attention to road surface as they would do under real riding conditions in order to detect hazards (e.g., potholes, debris or other feature of the road that can impact motorcycle riders' safety). The frontal aperture of the virtual helmet was manipulated (5 sizes: $\left[1,13,26,39\right.$, and $\left.52^{\circ}\right]$ corresponding to the angle subtended at the motorcyclist virtual point of view between the upper and lower black strips depicted on the screen) to vary the vertical dimension of the field of view of the riders. Those dimensions respectively correspond to $1,25,50,75$, and $100 \%$ of visor's minimal vertical dimensions imposed by European standards (ECE/TRANS/505 RV.1/Add.21/Rev.4, 2002). The task instructions (in terms of speed) given to participants were also varied. The manipulation was used to vary the eccentricity of the visual information to be scanned by riders. In the Free condition, participants were free to ride at their preferred speed. In the Speedometer condition, participants were instructed to drive at a constant speed of $90 \mathrm{~km} / \mathrm{h}$, which required checking the speedometer located on the handlebars, thus increasing the eccentricity of task-relevant visual information.

The standard deviation of the motorcycle's lateral distance from the red and white middle line and of its speed were used as dependent measures to characterize riding performance. Both variables were derived off-line from the time course of motorcycle's 2D positions collected during each ride by the virtual engine. These data were analyzed in separate $2 \times 5$ repeated measures ANOVAs with task and vertical aperture as the factors.

\section{RESULTS}

Figure 2 shows the standard deviation of the lateral distance from the middle line for the two different task conditions. The ANOVA performed on these data revealed a significant main effect of visor aperture, $\mathrm{F}(4,28)=19.2, \mathrm{p}=.000$, and a significant task $\times$ visor aperture interaction, $\mathrm{F}(4$, $28)=9.28, p=.000$. The main effect of task was marginally significant, $F(1,7)=5.18, p=.057$. Posthoc comparisons revealed that the standard deviation of distance was significantly lower in the Free condition (as compared to the Speedometer condition) for the $1[\mathrm{t}(7)=2.9, \mathrm{p}=.023]$ and $13 \mathrm{deg}$ apertures $[\mathrm{t}(7)=2.6, \mathrm{p}=.035]$. There was no significant differences for the 26, 39 and $52 \mathrm{deg}$ apertures (p's all $>0.1)$. 


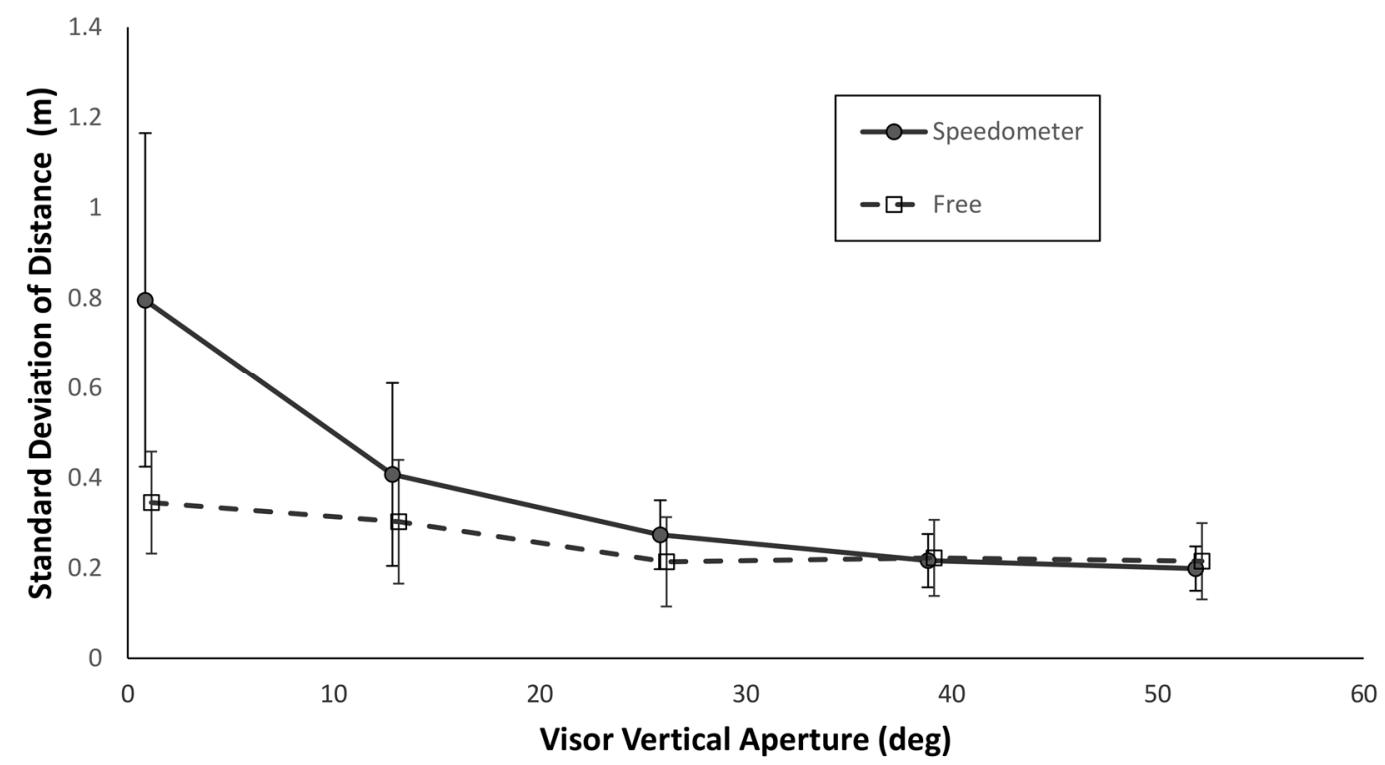

Figure 2. Mean standard deviation of lateral distance

Figure 3 shows the standard deviation of driving speed for the two different task conditions. The ANOVA performed on these data revealed only a significant main effect of task, $\mathrm{F}(2,7)=10.09$, $\mathrm{p}=.016$. This occurred because variability was generally lower in the speedometer condition. Posthoc comparisons revealed that the standard deviation of speed was significantly lower in the Free condition (as compared to the Speedometer condition) for the $1[\mathrm{t}(7)=2.8, \mathrm{p}=.02], 13[\mathrm{t}(7)=2.7$, $\mathrm{p}=.028$,] and $26 \mathrm{deg}[\mathrm{t}(7)=2.6, \mathrm{p}=.035$,] apertures while there was no significant difference for either the 39 or 52 deg apertures (p's both $>0.5$ ).

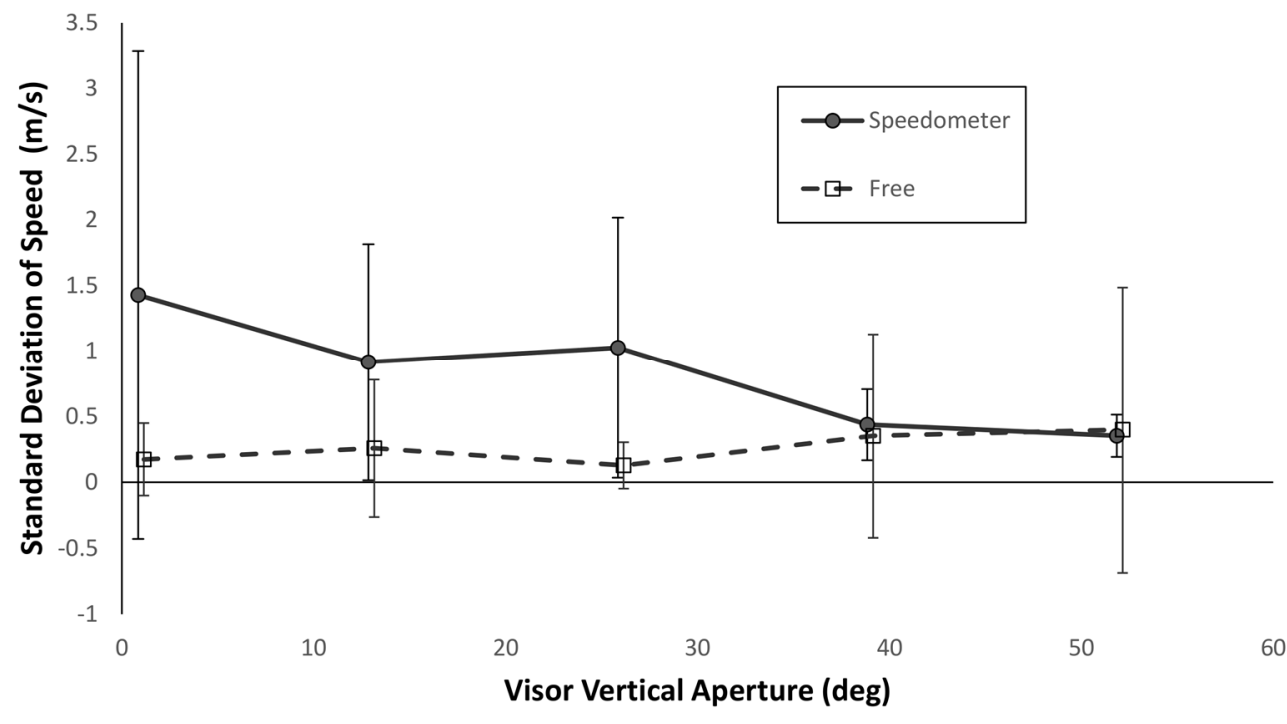

Figure 3. Mean standard deviation of speed 


\section{DISCUSSION}

While reducing the size of the frontal aperture of a helmet can help to make it stronger structurally, this reduction could potentially have dangerous consequences for perceptual-motor control. In the present study, we systematically varied the vertical extent of the aperture in a motorcycle simulator using a task which required the rider to steer around bends. Given that it has been hypothesized that effective steering requires the use of visual information from two points distributed vertically in the driver's field of view (a near point directly in front of the vehicle and a far point such as the tangent point of the upcoming bend; Salvucci \& Gray, 2004), it was hypothesized that the steering performance would be impaired at small vertical apertures.

As can be seen in Figure 2 for the free driving condition this did occur as the variability of position was greater when the vertical aperture was smaller. As predicted the effect of vertical aperture size was stronger when the driving task required checking the speedometer mounted on the handlebars. As can be seen in Figures 2 and 3, both variability in lateral position and variability in speed were significantly greater in the Speedometer task than in the Free task - with this difference being largest for the smaller aperture sizes. The speed variability result paradoxically suggests that speedometer checking does not assist participants in stabilizing their riding speed when their field of view was reduced. Taken together, these results suggest that the strategy used by riders was disturbed when the speedometer checking was required, most likely due to the conflict between monitoring the visual information needed for steering and the speedometer.

From a perceptual-motor strategy point of view, our study provides insight into the generalizability of the two-point visual control of steering to motorcycle riding. The deterioration of driving performances when manipulating the field of view, i.e., decreasing visor vertical dimensions leading drivers to experience difficulties in maintaining their position in the lane and speed, suggests that effective riding performances requires using both far and near visual information. The present study thus provides evidence that the perceptual variables and law of control identified by Salvucci \& Gray (2004) for car driving can be extended to motorcycle riding despite the presence of additional visual and musculoskeletal constraints related to motorcycle helmet and riding position. This suggests that the "two visual point steering control" is a perceptual-motor principle used for steering in curve independently of effectors or agents variations, just as the Constant Bearing Angle strategy in the domain of mobile-interception tasks (e.g., Morice, François, Jacobs, \& Montagne, 2010).

In terms of design recommendations the present study suggests that the vertical aperture size should be not be reduced below $39 \mathrm{deg}$. In future studies we plan to investigate how rider head movements are used to compensate for changes in aperture size, how the effects presented here generalize to other riding positions (e.g., Sportive, Custom) and whether similar effects of visor aperture are observed for experienced motorcycle riders.

\section{CONCLUSIONS}

Whereas standards simply define a motorcycle helmet as "a protective device designed to protect the head in the event of an impact" (World Health Organization, 2006), we provide evidence that 
helmets should be also designed so that they do not dangerously affect the wearer's ability to pick up near and far information needed for effective steering. The results of the present study indeed provided an applied insight on how helmet related perceptive constraints and motorcycle related motor constraints are dealt with while riding along curving roadways. We also provide evidence that the near and far point model of steering can be extended to motorcycle driving.

\section{REFERENCES}

Abbas, A. K., Hefny, A. F., \& Abu-Zidan, F. M. (2012). Does wearing helmets reduce motorcycle-related death? A global evaluation. Accident; analysis and prevention, 49, 249 252. doi:10.1016/j.aap.2011.09.033

Bogerd, Cornelis Peter, Carley, M., Crundall, D., Otte, D., Shahar, A., Shinar, D., Bruhwiler, P. A. (2010). COST Action 357: accident prevention options with motorcycle helmets. St. Gallen: Empa.

ECE/TRANS/505 RV.1/Add.21/Rev.4. Prescriptions uniformes relatives à l'homologation des casques de protections et de leurs écrans pour conducteurs et passagers de motocycles et de cyclomoteurs., E/ECE/TRANS/505 Rv.1/Add.21/Rev.4 (2002).

Land, M., \& Horwood, J. (1995). Which parts of the road guide steering? Nature, 377(6547), 339-340. doi:10.1038/377339a0

Morice, A. H. P., François, M., Jacobs, D. M., \& Montagne, G. (2010). Environmental constraints modify the way an interceptive action is controlled. Experimental Brain Research. 202(2), 397-411.

McKnight, A. J., \& McKnight, A. S. (1995). The effects of motorcycle helmets upon seeing and hearing. Accident Analysis \& Prevention, 27(4), 493-501.

Salvucci, D. D., \& Gray, R. (2004). A two-point visual control model of steering. Perception, 33, 1233-1248.

World Health Organization. (2006). Helmets a road safety manual for decision-makers and practictioners. Geneva: World Health Organization.

http://public.eblib.com/EBLPublic/PublicView.do?ptiID=284750 